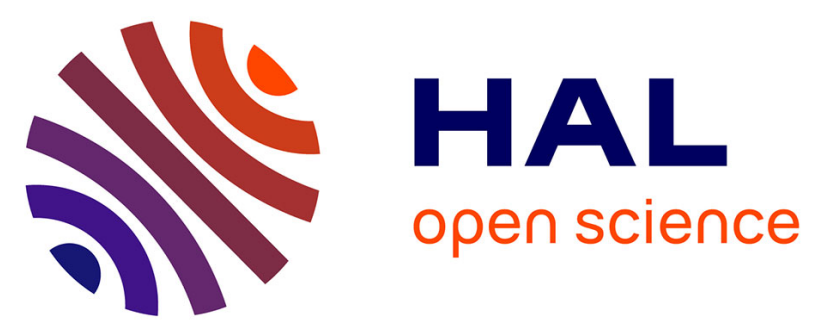

\title{
Intrathalline Metabolite Profiles in the Lichen Argopsis friesiana Shape Gastropod Grazing Patterns
}

\author{
Alice Gadea, Anne-Cécile Le Lamer, Sophie Le Gall, Catherine Jonard, \\ Solenn Ferron, Daniel D. Catheline, Damien Ertz, Pierre Le Pogam, Joël \\ Boustie, Françoise Lohézic-Le Dévéhat, et al.
}

\section{To cite this version:}

Alice Gadea, Anne-Cécile Le Lamer, Sophie Le Gall, Catherine Jonard, Solenn Ferron, et al.. Intrathalline Metabolite Profiles in the Lichen Argopsis friesiana Shape Gastropod Grazing Patterns. Journal of Chemical Ecology, 2018, 44 (5), pp.471-482. 10.1007/s10886-018-0953-1 . hal-01806586

\section{HAL Id: hal-01806586 \\ https://hal-univ-rennes1.archives-ouvertes.fr/hal-01806586}

Submitted on 19 Jul 2018

HAL is a multi-disciplinary open access archive for the deposit and dissemination of scientific research documents, whether they are published or not. The documents may come from teaching and research institutions in France or abroad, or from public or private research centers.
L'archive ouverte pluridisciplinaire HAL, est destinée au dépôt et à la diffusion de documents scientifiques de niveau recherche, publiés ou non, émanant des établissements d'enseignement et de recherche français ou étrangers, des laboratoires publics ou privés. 
2

3

\section{INTRATHALLINE METABOLITE PROFILES IN THE LICHEN Argopsis friesiana SHAPE} GASTROPOD GRAZING PATTERNS.

Alice GADEA ${ }^{1,2}$, Anne-Cécile LE LAMER ${ }^{3}$, Sophie LE GALL ${ }^{4}$, Catherine JONARD ${ }^{5}$, Solenn FERRON ${ }^{1}$, Daniel CATHELINE ${ }^{6}$, Damien ERTZ7 ${ }^{7}$, Pierre LE POGAM ${ }^{8}$, Joël BOUSTIE¹, Françoise LOHEZIC - LE DEVEHAT ${ }^{1, \dagger^{, *}}$ and Maryvonne CHARRIER ${ }^{2,}$, $^{*}$

${ }^{1}$ Univ Rennes, CNRS, ISCR (Institut des Sciences Chimiques de Rennes) - UMR 6226, F35000 Rennes, France

${ }^{2}$ Univ Rennes, CNRS, ECOBIO (Ecosystèmes, biodiversité, évolution) - UMR 6553, F-35000 Rennes, France

${ }^{3}$ Univ Toulouse 3 Paul Sabatier, IRD, Pharma-Dev - UMR 152, F-31400 Toulouse, France

${ }^{4}$ INRA, BIA (Biopolymers Interactions Assemblies) - UR 1268, F-44316 Nantes, France

${ }^{5}$ INRA, BIA (Biopolymers Interactions Assemblies) - UR 1268, F-35650 Le Rheu, France ${ }^{6}$ INRA, USC 1378, F-35042 Rennes Cedex, France

${ }^{7}$ Botanic Garden Meise, Department Research, Nieuwelaan 38, B-1860 Meise, Belgium.

${ }^{8}$ Univ Rennes, CNRS, IETR (Institut d'Electronique et de Télécommunications de Rennes) UMR 6164, F-35000 Rennes, France † These authors contributed equally to this paper

* Corresponding authors: Françoise LOHEZIC - LE DEVEHAT (francoise.le-devehat@univrennes1.fr_; +332 232348 16; ORCID: 0000-0003-4307-4942) and Maryvonne CHARRIER (maryvonne.charrier@univ-rennes1.fr ; + 332232350 45) 
24 Abstract-Lichen-gastropod interactions generally focus on the potential deterrent or toxic role of 25 secondary metabolites. To better understand lichen-gastropod interactions, a controlled feeding 26 experiment was designed to identify the parts of the lichen Argopsis friesiana consumed by the 27 Subantarctic land snail Notodiscus hookeri. Besides profiling secondary metabolites in various 28 lichen parts (apothecia, cephalodia, phyllocladia and fungal axis of the pseudopodetium), we 29 investigated potentially beneficial resources that snails can utilize from the lichen 30 (carbohydrates, amino acids, fatty acids, polysaccharides and total nitrogen). Notodiscus hookeri 31 preferred cephalodia and algal layers, which had high contents of carbohydrates, nitrogen, or 32 both. Apothecia were avoided, perhaps due to their low contents of sugars and polyols. Although 33 pseudopodetia were characterized by high content of arabitol, they were also rich in medullary 34 secondary compounds, which may explain why they were not consumed. Thus, the balance 35 between nutrients (particularly nitrogen and polyols) and secondary metabolites appears to play 36 a key role in the feeding preferences of this snail.

38 Key Words-Herbivory, chemical ecology, lichen-gastropod interactions, Subantarctic islands, 39 Stereocaulaceae, Notodiscus hookeri. 


\section{INTRODUCTION}

44 Lichens are above all a lifestyle generally presented as a stable organism corresponding to the 45 symbiotic association of fungi with photobionts (Gargas et al. 1995). Fungal symbioses with algal 46 or cyanobacterial photobionts are called chloro- and cyanolichens, respectively. Sometimes the 47 mycobiont coexists with both green algae and cyanobacteria and forms tripartite lichens, 48 referred to as cephalolichens, because cyanobacteria are located inside specialized fungal 49 compartments (cephalodia).

50 In a lichen thallus, green algae produce polyols while cyanobacteria synthesize sugars. These 51 photosynthetically produced carbohydrates may be metabolized by the fungus partner into 52 mannitol and/or arabitol (Richardson et al., 1968). The mycobiont also produces secondary 53 metabolites (or specialized metabolites) that accumulate in the cortex or in the medullar layer 54 (Molnár and Farkas 2010). In most chlorolichens, the acetyl-polymalonyl pathway leads to the 55 synthesis of secondary metabolites, mainly phenolic compounds such as depsides and 56 depsidones (Stocker-Wörgötter 2008). In most cyanolichens and in cephalodia containing 57 cyanobacteria, terpenoids and mycosporines predominate (Rundel 1978; Roullier et al. 2011). 58 The co-occurrence of two photobionts in cephalolichens is reflected by the diversity and 59 allocation of metabolites produced, cephalodia being devoid of phenolic compounds, which 60 are found in the other parts of the thallus, but rich in N-containing compounds (Roullier et al. 61 2011). As a general trend, a higher content of nitrogen occurs in cephalo- and cyanolichens as 62 the atmospheric nitrogen fixed by the cyanobacteria is converted to amino acids by the 63 mycobiont (Rai and Bergman 2002).

64 Phenolic compounds in lichens have various roles. Some may deter lichen feeders such as 65 molluscs (Coker 1967; Asplund et al. 2010b), mammals (Cook et al. 2007; Nybakken et al. 2010) 66 and arthropods (Gerson 1973; Wieners et al. 2018). Various physical and chemical factors may 67 influence the attractiveness of lichens for lichenivorous organisms, such as roughness and 3 
68 growth form, occurrence of defence compounds and $\mathrm{N}$-fixing ability of the lichen (Asplund and 69 Wardle 2016). In studies focussing on interactions between plants and phytophagous animals, 70 different hypotheses have been proposed postulating a trade-off between the cost of operating 71 chemical defence and the benefit of enhancing survival. In his work on plant-herbivore 72 coevolution, McKey (1974) developed the "optimal defence theory" (ODT) which was later 73 applied by Asplund et al. (2010b) to lichen-gastropod interactions. This theory predicts that 74 secondary metabolites in plants are allocated proportionally to the risk of attack for a specific 75 tissue and the value of this tissue in terms of the reduction in fitness that its loss would entail. In 76 many lichens, secondary metabolites occur in higher concentrations in reproductive parts, 77 whether sexual (apothecia) or asexual (isidia, soralia), than in the rest of the thallus, or occur 78 only in these reproductive parts. (Hyvärinen et al. 2000). Rundel (1978) conceptualized another 79 hypothesis, suggesting that the higher the nitrogen content, the higher is the lichen's palatability. 80 Hence, lichens with low nitrogen content and high concentration of secondary metabolites 81 (particularly depsides and depsidones) should suffer low grazing. Rundel's hypothesis was 82 confirmed for most chlorolichens, which were indeed more grazed after non-destructive removal 83 of the secondary metabolites by the acetone-rinsing method (Solhaug and Gauslaa 2001; 84 Asplund and Wardle 2013). Conversely, Rundel's theory was not validated for some 85 cyanolichens which were not consumed although characterised by high nitrogen levels and low 86 content of secondary chemicals. The presence of intracellular repulsive compounds or of 87 metabolites not extractable by acetone (i.e. mycosporines) was hypothesized, due to the 88 persistence of a deterrent effect after acetone rinsing (Solhaug and Gauslaa 2012).

89 Lichens are widespread from cold to tropical habitats, from wet to xeric conditions and in 90 nutrient-poor habitats, such as alpine and polar areas, where they are often dominant (Sanders 91 2001). In Subantarctic islands, where lichens are abundant, it could be important for 92 phytophages to exploit such an abundant resource and thus allow an expansion into new 93 environments. The Subantarctic land snail Notodiscus hookeri, an exclusive lichen feeder, is 4 
94 particularly widespread on Crozet (Possession Island) and Kerguelen Archipelagos (Charrier et 95 al. 2013). This species provides an appropriate model organism for studying lichen-gastropod 96 interactions. Recently, Gadea et al. (2017) demonstrated the generalist status of $N$. hookeri by a 97 comparative study of snail metabolism after feeding on Usnea taylorii (chlorolichen) and 98 Pseudocyphellaria crocata (cyanolichen). These authors observed several snail strategies to 99 overcome potentially toxic metabolites present in lichens.

100 Optimal foraging in generalist species, such as most terrestrial gastropods, requires a balance between the access to useful nutrients and the need to overcome toxic compounds. Therefore, the snail should be able to select lichen parts according to their nutritional quality and to avoid toxic compounds. In this study, we focussed on the cephalolichen Argopsis friesiana Müll. Arg. (Stereocaulaceae), a tufty $\leq 4 \mathrm{~cm}$ tall species, widespread in low-nutrient, windy fell-fields of Subantarctic islands (Lamb 1974; Galloway 1980). Argopsis friesiana is characterized by a rigid pseudopodetium, cylindric-corraloid phyllocladia, concave-scutelliform apothecia and botryose cephalodia. Its main photobiont is a green alga (Trebouxia s. lat.), its secondary autotrophic partner is the cyanobacterium Stigonema sp., located in the cephalodia. To understand how this snail could benefit from eating this lichen, we examined the influence of lichen chemistry on snail nutrition. For this purpose, we explored how the metabolites were distributed in the different parts of the lichen A. friesiana and how this distribution shaped the snail grazing patterns. Intrathalline sectorization of the symbiotic partners facilitated the separation of $A$. friesiana into four different parts to be analysed separately. Three hypotheses were tested: The snail (1) avoids lichen parts with high concentrations of secondary metabolites, (2) prefers lichen parts that are rich in essential nutrients (sugars, amino acids, fatty acids, polysaccharides) and (3) prefers thallus parts rich in nitrogen. 
Biological Material. Argopsis friesiana Müll. Arg., endemic to the Subantarctic islands in the

Indian Ocean, was collected on Possession Island (Crozet archipelago) at "Le Donjon » $\left(46^{\circ} 25^{\prime} 01^{\prime \prime} \mathrm{S}, 51^{\circ} 50^{\prime} 15^{\prime \prime} \mathrm{E}, 200 \mathrm{~m}, \mathrm{DON}\right)$ during the austral summer 2015 . The identification of the species was confirmed by one of us (DE) by comparison with type material and the species was sequenced for the first time. A sequence of nuclear ribosomal internal transcribed spacer (ITS) of the material used in this study was deposited in GenBank (MG947382) as a reference for our material because ITS is used as a universal DNA barcode marker for fungi (Schoch et al. 2012). The species resembles the sympatric Stereocaulon cymosum Cromb., which differs by its transversely septate ascospores versus muriform ascospores in A. friesiana. Voucher specimens were deposited at the herbarium of the Faculty of Pharmacy of Rennes 1, Department of Pharmacognosy and Mycology, under the reference REN000140.

To investigate the palatability of $A$. friesiana, snails were collected from sites for which we had an official collection permit. Seventy-five adults (shell size $\geq 5 \mathrm{~mm}$ ) were collected during

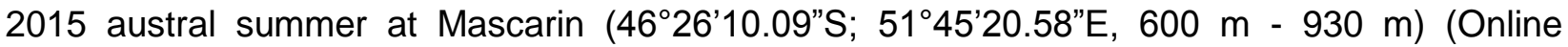
Resource 1, Fig. S1). The specimens, found in fell-fields including the lichen habitats, belong to the soft-shell ecophenotype described by Charrier et al. (2013).

Lichen Preparation. Argopsis friesiana was cut into four parts as explained in Fig. 1a. The pseudopodetium consists of (i) a central axis, the medulla, made up of compact fungus hyphae (Pf) and (ii) an outer layer with fungi and green algae (Pa). Phyllocladia are the terminal branchlets of pseudopodetia containing algae (Ph). Cyanobacteria live inside numerous black cephalodia $(\mathrm{Ce})$, external gall-like structures emerging laterally from the pseudopodetium. 141 Apothecia, the sexual reproductive parts of the lichen, are scattered on the upper surface of the 142 thallus. The underside of the apothecium is similar to the algal layer of the pseudopodetium. For 143 chemical analyses, algal layer and phyllocladia were combined because of their structural 144 similarity. 
Experimental Design. Snails were reared in boxes $(7.5 \times 6 \times 4.5 \mathrm{~cm})$ under a thermal cycle, $6^{\circ} \mathrm{C}$ during night (10h) and $10^{\circ} \mathrm{C}$ during day (14h). A moist synthetic foam in the bottom (5 mm thick) ensured snail activity. After four days of starvation, the snails $(n=75)$ were divided into 15 groups of five individuals. They were allowed to feed upon $A$. friesiana for two nights ( $48 \mathrm{~h}$ experiment). Each group received a fertile thallus, on which apothecia and cephalodia were counted. Snail consumption was controlled after one night and damage was measured after two nights under a stereomicroscope (Stemi 2000-C, Zeiss, France).

Level of grazing (LD) was adapted from Nimis and Skert (2006) and measured as follows: LD0 intact, LD1= low grazing $(<25 \%)$, LD2=medium damage $(>25-50 \%$ consumed) and LD3 $=$ high damage $(>50 \%)$. For pseudopodetia, grazing on the algae-containing cortical layer (Pa) was assessed separately from that on the fungus axis (Pf) and the levels of grazing were defined as: $L D 0=$ algal layer and fungal axis of the pseudopodetia remained intact, LD1 = minimum damage (algal layer consumed $<25 \%$, fungal axis intact), LD2 $=$ medium damage (algal layer consumed $<50 \%$, fungal axis intact), LD3 $=$ high damage (algal layer $\mathrm{Pa}$ and fungal axis $\mathrm{Pf}$ consumed, $>50 \%$ ). To assess the damage to cephalodia and apothecia, a grazing ratio was determined as follows: Number of apothecia or cephalodia with grazing marks / Number of apothecia or cephalodia available. To compare grazing on cephalodia and apothecia with damage to algal layer, fungal axis and phyllocladia, the levels described above (LD in \%) were 164 utilized. 
Sample Preparation for Chemical Analyses. To determine a sectorial distribution of metabolites,

three samples of several $A$. friesiana thalli (about one gram each) were prepared. Each thallus was cut into the four parts apothecia, cephalodia, fungal axis and algal layers. The 12 samples were ground separately with mortar and pestle in liquid nitrogen. To quantify secondary metabolites, freeze-dried samples (40 mg each) were used. Primary metabolites, including amino acids, free sugars and polyols, were analysed with $10 \mathrm{mg}$ of each thallus part, while 50 $\mathrm{mg}$ of each part was needed for quantification of fatty acid and sugar-forming polysaccharides and for determination of nitrogen content.

Secondary Metabolite Profiling. Each part of the air-dried lichen thalli was extracted with 100\% acetone $(3 \times 500 \mu \mathrm{L})$. Acetone extracts were solubilized in tetrahydrofuran (THF), filtered and injected $\left(10 \mu \mathrm{L}\right.$ at $\left.0.5 \mathrm{mg} \cdot \mathrm{mL}^{-1}\right)$ in a Liquid Chromatography - Diode Array Detector (LC-DAD) (Shimadzu®, Marne La Vallée, France, LC-20AD SP, injector SIL-20A HI, column oven CTO20A, diode array detector SPD-M20A) and a mass spectrometer (MS) (Advion® expression CMS, Ithaca, USA). Ionization was performed by negative-ion mode electrospray (ESI-). A gradient system was applied: A $(0.1 \%$ formic acid in water $)$ and $B(0.1 \%$ formic acid in acetonitrile) for $48 \mathrm{~min}$ on a $\mathrm{C}_{18}$ column (Phenomenex®, Kinetex $2.6 \mu \mathrm{C}_{18} 100 \mathrm{~A}$, temperature $40^{\circ} \mathrm{C}$ ) at a flow rate of $0.5 \mathrm{~mL} \cdot \mathrm{min}^{-1}$ : initial, $20 \% \mathrm{~B}$; T $0-5 \mathrm{~min}, 20 \%$ B linear; T $30 \mathrm{~min} 80 \% \mathrm{~B}$; T 35-42 min, 100\% B linear; T 45-48 min, 20\% B linear. Linear equations based on the calibration curve were used to quantify atranorin and the results were expressed in $\mathrm{mg} \cdot \mathrm{g}^{-1}$ Dry Mass (DM). Atranorin (JB/A/142) used for calibration belong to the library of single lichenic compounds of UMR 6226, being isolated during previous phytochemical investigations. For the other metabolites, also detected by UV on HPLC chromatograms, a relative quantification was performed, by multiplying the area under the curve (AUC) and the extraction yield of the lichen extract. Full scan mass spectra were recorded in negative-ion mode in a mass range of 100 to $1200 \mathrm{Da}$, applying the following parameters: detector gain 1200, ESI voltage $3.5 \mathrm{kV}$, capillary 8 
voltage $180 \mathrm{~V}$, source voltage $20 \mathrm{~V}$, source voltage dynamic $20 \mathrm{~V}$, nebulizer gas pressure 60

psig, desolvation flow gas rate $4 \mathrm{~L} \cdot \mathrm{min}^{-1}$, capillary temperature $250^{\circ} \mathrm{C}$ and gas temperature $20^{\circ} \mathrm{C}$. Data processing and evaluation for MS measurement were performed with the Data and Mass Express 2.2.29.2 software (Advion). As a complement to LC-DAD-MS experiments, in situ analyses of each part of the lichen were made using the ambient air source DART-HRMS, enabling the chemical profiling of unprocessed pieces of thallus (Le Pogam et al. 2015, 2016); more detailed protocol in Online Resource 2). The identification of metabolites was done against compounds formerly identified within the genus Argopsis and the family Stereocaulaceae (Bodo and Molho 1974; Lamb 1974; Galloway 1980).

Primary Metabolite Profiling. Soluble carbohydrates, polyols and amino acids were extracted from each part of the lichen, following the methodology of Gravot et al. (2010). Twenty mM of adonitol (soluble carbohydrates and polyols) and 10mM of 3-aminobutyric acid (BABA) (amino acids) were used as internal standards. Soluble carbohydrates and polyols were profiled by a Gas Chromatography - Flame Ionization Detector (GC-FID) (Thermo-Fisher Scientific, Waltham, CA, USA) according to Adams et al. (1999) and Lugan et al. (2009). Amino acids were detected with an Ultra High Performance Liquid Chromatography - Diode Array Detector (UPLC-DAD, Waters), by using an AccQ-Tag Ultra derivatization kit (Waters Corporation, Milford, MA, USA) following the protocol described in Gravot et al. (2010). The metabolites were identified from their retention time by comparison with external standards. Concentrations $\left(\mathrm{mg} \cdot \mathrm{g}^{-1} \mathrm{DM}\right)$ were obtained on the basis of internal standards.

214 Fatty Acids Profiling. Samples were extracted three times in a parallel synthesis apparatus 215 (Heidolph Parallel Synthesis Apparatus ${ }^{\circledR}-$ Instruction Synthesis 1, France), for $1 \mathrm{~h}$ each, with 216 chloroform/methanol $(2: 1, \mathrm{v} / \mathrm{v}, 6 \mathrm{~mL})$ at $80^{\circ} \mathrm{C}$, under constant shaking at $700 \mathrm{rpm}(\mathrm{Vu}$ et al. 2016). To quantify fatty acids (FAs), $100 \mu \mathrm{g}$ of heneicosanoic acid (C21:0) were added as an 
internal standard. The organic phase containing the total lipids was recovered and evaporated to dryness under a nitrogen flow. Sample derivatization and GC-FID/GC-MS (Agilent 6890N, Toulouse, France) analyses were conducted using the protocol of Vu et al. (2016). Identification of fatty acid methyl esters (FAMEs) was based on the retention times. The quantity of total FAs

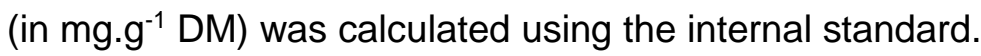
set at $100^{\circ} \mathrm{C}$ for $20 \mathrm{~min}$, followed by rinse volume of $150 \%$, and a purge time $\left(\mathrm{N}_{2}\right)$ of $30 \mathrm{~s}$. Cells of the ASE® 350 containing AIRs were dried at $40^{\circ} \mathrm{C}$ overnight under vacuum over $\mathrm{P}_{2} \mathrm{O}_{5}$, prior to

Total Nitrogen (TN) Measurement. TN (in \% of DM) was determined with an automated dry 242 combustion method (Dumas method ; Rhee 2001) using an elemental analyser (vario MICRO 243 cube, Elementar Analysensysteme, Hanau, Germany). 
Statistical Analyses. A Fisher's exact test was applied to LD values obtained for damage to algal layer and fungal axis of the pseudopodetia, phyllocladia, cephalodia and apothecia, in order to compare the observed frequencies among lichen parts. In the text, mean \pm standard deviation is given. A Spearman correlation was used to compare LD values with the number of cephalodia or apothecia carried out by the thallus.

To analyse the metabolic data, we first proceeded to fourth-root transformation of the values, centring and autoscaling, because null values and great differences in concentrations according to metabolite profiles were observed (van den Berg et al. 2006). Powered Partial Least Squares - Discriminant Analysis (PPLS-DA) was performed on the normalized values to discriminate the four parts of $A$. friesiana on the basis of their metabolic profiles (function $\mathrm{cppls}($ ), package "pls" (Indahl et al. 2009)). The significance of the discrimination was tested using a cross-model validation (functions MVA.cmv() and MVA.test()), developed in the package "RVaidememoire" (Hervé 2016).

All statistical analyses were made using R software V. 3.4.0 (R Core Team 2017).

\section{RESULTS}

Snail Feeding Preferences. Snails from Mascarin site had shell sizes of $4.9 \pm 0.5 \mathrm{~mm}$ (mean \pm s.d.). Shell size did not differ among groups ( $\mathrm{n}=15 \times 5$ individuals per group; ANOVA, $F_{14,60}=$ $0.415, P=0.964)$.

Apothecia were completely avoided by $N$. hookeri (Fig. 1a-2). Similarly, the fungal axis was not consumed, while the cortical algal layer and phyllocladia were grazed (Fig. 1a-2). The levels of damage (LD) on cortical algal layer and phyllocladia ranged from $<25 \%$ to $<50 \%$ and were similar (Fisher's exact test, $\mathrm{P}=0.710$ ) (Fig. 2). Cephalodia were the preferred part, more than $40 \%$ of them being highly damaged (= LD3) and significant grazing differences being observed between cyanobacterial (cephalodia) and green algal parts (cortical algal layer and 
phyllocladia) of the lichen (Fisher's exact tests, $\mathrm{P} \leq 0.001$ ) (Fig. 1b-2, Fig. 2). The mean ( \pm s.e.)

number of cephalodia grazed reached $4.9 \pm 0.5$ in 48 hours and was dependent on the total number of cephalodia per thallus (Spearman's rank correlation, rho $=0.59, \mathrm{P}=0.021$ ).

Metabolite Profiling of A. friesiana. The chemical profiles in secondary metabolites of each part of the lichen $A$. friesiana were established by LC-DAD-ESI-MS from their acetone extracts. Three main compounds were identified: the depside atranorin $(\mathrm{m} / \mathrm{z} 373)$ and two chlorinated compounds (Table 1, Fig. S2). These two chlorodepsidones were identified as the dichlorinated $\operatorname{argopsin}(\mathrm{m} / \mathrm{z} 395)$ and as the trichlorinated caloploicin $(\mathrm{m} / \mathrm{z} 401)$ through isolation and spectroscopic data analysis (Purification protocol and NMR data are given in Online Resource 2, Fig. S3-S4, Table S1-S2). In situ DART-HRMS analysis confirmed identification of chlorinated compounds detected by LC-DAD-MS from unprocessed pieces of lichens through exact mass measurements (Online Resource 2, Table S3). Algal layers had the highest concentration of secondary metabolites, particularly for atranorin, reaching $10.6 \pm 2.3 \mathrm{mg} \cdot \mathrm{g}^{-1} \mathrm{DM}$. In comparison, atranorin varied from $0.5 \pm 0.2 \mathrm{mg} \cdot \mathrm{g}^{-1} \mathrm{DM}$ in cephalodia to $1.1 \pm 0.6 \mathrm{mg} \cdot \mathrm{g}^{-1} \mathrm{DM}$ in apothecia. In pseudopodetia, the medullar caloploicin with argopsin accounted for about two-thirds of the secondary metabolites, while atranorin alone approximately reached this proportion in apothecia and in green algae-containing tissues (Table S4).

Among all detectable metabolites, 36 were found in apothecia, 33 in the medullar axis of pseudopodetia, 41 in phyllocladia and algal layer of pseudopodetia and 42 in cephalodia (Table 1). The multivariate analysis (PPLS-DA) showed partitioning in the metabolite profiles among parts of the lichen A. friesiana (Fig. 3a, Fig. 3b, contributions to PC1 axis, Online Resource 3 Fig. S5). The cross model validation used for the discrimination of the lichen parts (8 components, 999 permutations, $\mathrm{NMC}=0.042 ; \mathrm{P}=0.001)$ indicated statistically different chemical profiles. The PC2 axis distinguished the presence or the absence of photobionts while 
the biont identity was discriminated on the first axis (PC1). Green algal layers were characterized by proline and GABA, and by the secondary metabolites atranorin, argopsin and caloploicin. On the opposite side of the first axis, discrimination of the cephalodia was mainly due to trehalose, $F A_{\text {unsat }}(\mathrm{n}-7)$ family, galactose, mannose and rhamnose from polysaccharides, amino acids such as lysine and arginine, and by high nitrogen concentration (TN). The position of cephalodia was negatively correlated with the abundance in glucose issued from the degradation of polysaccharides. On the second axis (contribution to PC2 axis, Online Resource Fig. S6), the position of apothecia was negatively associated with the occurrence of amino acids and polyols (especially arabitol) and a positive but limited association with some FA (FAsat and $F A_{\text {unsat }}(n-9)$ families) was observed. The position of the fungal axis of pseudopodetia on the third axis (PC3) was positively correlated with the presence of fatty acids (FA sat, C18:2 n-6, C16:1 n9), mannitol) and a-alanine (Fig. 3c, Fig. 3d, contributions to PC3 axis, Online Resource 3 Fig. S7).

\section{DISCUSSION}

Among the three major secondary metabolites detected in Argopsis friesiana, the depside atranorin and the chlorodepsidone argopsin have already been reported in this species (Huneck and Lamb 1975). Yosioka et al. (1973) revealed the chlorodepsidone caloploicin in the genus Caloplaca, but here, for the first time, caloploicin has been isolated from the genus Argopsis with the complete NMR assignment for this compound (Online resource 2).

When consuming A. friesiana, N. hookeri at first meets external layers high in secondary 318 metabolites. Despite the abundance of atranorin in the cortex, it had no deterrent effect on snail 319 grazing. In phytophagous arthropods, atranorin was reported to elicit a significant avoidance 320 (Nimis and Skert 2006) or to reduce growth of insect larvae (Slansky 1979; Pöykkö et al. 2005) 321 but no protective effect of atranorin was noticed in snails (Hesbacher et al. 1995; Gauslaa 2005). 
In the soft bodies of various snail species, Hesbacher et al. (1995) detected a compound presumably originating from hydrolysis of atranorin and suggested its sequestration in snail tissues. While the retention of lichen compounds in bodies of snails was not analysed as part of the current study, this hypothesis is consistent with the previously reported ability of $N$. hookeri to hydrolyse ester bonds of the tridepside tenuiorin, due to the alkalinity of its gut lumen (Gadea et al. 2017). According to Lawrey (2009), cortical compounds (i.e. atranorin in A. friesiana) are assigned a protective role against high irradiance, whereas a number of medullary secondary metabolites deter lichenivores. As caloploicin and argopsin are depsidones, they were expected to occur predominantly in the medulla. In A. friesiana, much higher concentrations of these compounds were found in the external green algal layers, but expressed in percentages they represented less than $25 \%$ of the detected secondary metabolites in this part. By contrast, caloploicin and argopsin reached $70 \%$ of the secondary metabolites found in the central axis of the pseudopodetia. The medulla of $A$. friesiana remained intact after snail feeding, consistent with a deterrent role of these compounds. This is in agreement with Asplund (2011), who demonstrated that snails avoid the medulla of Lobaria species due to the presence of depsidones.

According to the Optimal Defence Theory (McKey 1974; Asplund et al. 2010b), reproductive tissues should be well defended. However, our results did not support the theory. In A. friesiana, apothecia and cephalodia had similar concentrations of medullary secondary metabolites. Unlike cephalodia, apothecia were avoided by $N$. hookeri, suggesting that (i) other undetected toxic compounds deter snail grazing, or (ii) their avoidance may be due to low nutrient content, or (iii) the roughness of apothecia may present a physical barrier to radula motion. Therefore, the food choices made by $N$. hookeri cannot be explained simply by the avoidance of secondary metabolites, supporting the conclusion of Lawrey (1983). Other factors or compounds such as essential nutrients for snail growth and reproduction might be involved. 
Cephalodia and algal layers were selected by $N$. hookeri when given a choice among the

four parts of $A$. friesiana. These lichen parts were characterized by their richness in some nutrients: (i) polyols and free sugars, among which trehalose was encountered in cephalodia only, (ii) amino acids, among which proline was exclusive of algal layers. Avoidance of apothecia by the snail might be linked to their low content of phagostimulant compounds. However, we cannot explain why the snails did not consume the fungal axis of pseudopodetia. Although rich in arabitol, the fungal axis was characterized by a lack of diversity in nutrients compared to that found in apothecia. Moreover, the central axis made of compact hyphae, as well as apothecia, may be resistant to grazing. Indeed, the radular teeth of $N$. hookeri are smooth and more or less bulging or flat, features of non-specialized radulae potentially sensitive to rough (apothecia) and fibrous (fungal axis) textures (Fig. S8). By contrast, the soft and gelatinous structure of the cephalodia could promote grazing. This observation is in line with the study of Baur et al. (2000), who compared the ultrastructure of snail radulae and concluded that hook-shaped teeth, such as those of Chondrina clienta, are necessary to scrape efficiently on crustose lichens.

We demonstrated the high palatability of cephalodia and algal layers for $N$. hookeri and that the more numerous the cephalodia, the more consumed they were. Various factors could explain these feeding choices. Due to their low levels of defences, cephalodia may be preferred by snails (Renner 1982; Asplund and Gauslaa 2010). Second, the snails could acquire a balanced intake of essential nutrients by consuming several parts of the lichen with intrathalline chemical specificities. If so, the snail would have to perceive nutrient quality even in the case of sub-lethal toxicity particularly due to the occurrence of argopsin and caloploicin in A. friesiana. An ability to select foods that contain essential organic or mineral nutrients despite ingestion of secondary metabolites was evidenced in slugs by Cook et al. (2000) and in snails by Chevalier et al. (2003).

The glucose residues in polysaccharides, although they were half as abundant in cephalodia as in other parts, they suggested the presence of glucans, probably isolichenan ( $\alpha$ - 
glucan), as found for Stereocaulon ramulosum (Baron et al. 1991). The abundance of galactose and mannose units in the cephalodia could reflect the synthesis of galactomannan, a hypothesis supported by the description of these heteropolymers in Stereocaulon paschale (Baron et al. 1989). Because lichenan, mannan and galactomannan degrading-enzymes occur in land snails (Flari et al. 1995; Charrier and Rouland 2001), N. hookeri can probably exploit this source of glycosidic residues and thereby meet its energy needs. Indeed, gastropod metabolism is considered to be polysaccharide-orientated as energy is mainly provided by glycogen storage (Nicolai et al. 2012). Sugars and amino acids are also needed to synthetize mucus proteoglycans for snail locomotion, adhesion, body hydration and chemical communication $(\mathrm{Ng}$ et al. 2013). Because mucus production requires around $20 \%$ of ingested energy (Denny 1980), the consumption of food rich in potential mucin-like compounds would be beneficial to snail survival.

Two fatty acids (C16:1 n-7 and C18:1 n-7) discriminated cephalodia. FA $A_{\text {unsat }}(\mathrm{n}-7)$ family is specific to cyanobacteria (Rezanka and Dembitsky 1999; Vu et al. 2016), raising the question of whether the snail feeding preference for cyanobacteria is governed by phagostimulating properties of this FAs family. Lipids are mainly in cellular membranes, phospholipids and sterols representing over $80 \%$ of the total lipids (Van der Horst and Zandee, 1973). In A. friesiana, linoleic acid (C18:2 n-6) is by far the most available FA unsat for $N$. hookeri. Yet, Arakelova et al. (2009) reported more than $10 \%$ of linoleic acid in triglycerides in the digestive gland of phytophagous pond snails. These authors showed that linoleic acid and linolenic acid (C18:3 n3), were provided by the algal food and acted as precursors of long-chain C22 FAs that play a role in the activity of the pedal muscle.

Cephalodia were also characterized by their richness in $\mathrm{N}$, suggesting that the grazing preferences of $N$. hookeri were not reduced by nitrogen abundance. Asplund and Gauslaa (2010) showed that gastropods also preferred cephalodia when feeding on the foliose lichen Nephroma arcticum. By contrast, Asplund et al. (2010a) demonstrated species-specific reduction 
in lichen palatability following artificial $\mathrm{N}$ deposition, and Asplund and Wardle (2013) found that $\mathrm{N}$-enriched lichens were less palatable. However, these authors showed that the effect on consumption rate depended on an interaction between nitrogen-fixing ability and growth form. The cephalodiate and fruticose $A$. friesiana could be included in the group of fruticose $\mathrm{N}$-fixing species described by Asplund and Wardle (2013), which are consumed more than non- $\mathrm{N}$-fixing fruticose species. Hence, our results do not contradict those of Asplund and Wardle (2013). Because the snail tissues contain 10\% nitrogen (Speiser 2001), we hypothesize that $N$. hookeri should benefit from the higher $\mathrm{N}$ concentrations (1.6\%) in cephalodia than in other lichen tissues.

408 Studies on lichen-gastropod interactions have often examined only the repellent role of secondary metabolites, but we showed here that the contents in nitrogen and primary metabolites related compounds (such as amino acids, sugars and polyols) should not be underestimated. Moreover, physical criteria such as the hardness of lichens thalli could be able to modulate the chemical defence strategy of the snail. Additional study should focus on fatty acids of the snail's tissues to investigate the role of the lichen food in provisioning lipid components.

Conflict of Interest: The authors declare that they have no conflict of interest.

Acknowledgments-Aurélie BERNARD, Corentin DAUGAN and Nathalie MARNET are 419 acknowledged for their technical assistance. The authors are also indebted to David RONDEAU 420 for giving access to DART-HRMS (DReAM platform, IETR) and Arnaud BONDON and Sandrine 421 POTTIER (PRISM, BioGenOuest) for NMR material access. This work used analytical facilities 422 of the P2M2 platform for primary metabolites (amino acids and carbohydrates) analyses thanks 423 to Alain BOUCHEREAU. The field trip to the Subantarctic was funded by l'Institut Polaire Paul424 Émile Victor, Plouzané, France (IPEV, programme 136). Aude BOUTET and Julien 
TOMMASINO are warmly thanked for their help during the fieldwork. Prof. Yngvar GAUSLAA is

426

Funding-This research was funded by the French Polar Institute (Institut Polaire Paul-Émile Victor) within the context of the program 136 "SUBANTECO". Collecting and transport of specimens of the species Notodiscus hookeri were authorized by the Prefect of Ille-et-Vilaine, France, licence N³5-120 delivered in October 2015.

\section{REFERENCES}

Adams MA, Chen Z, Landman P, Colmer TD (1999) Simultaneous determination by capillary gas chromatography of organic acids, sugars, and sugar alcohols in plant tissue extracts as their trimethylsilyl derivatives. Anal Biochem 266:77-84. doi: 10.1006/abio.1998.2906

Arakelova ES, Chebotareva MA, Zabelinskii SA, Ivanova VP (2009) Effect of habitat and motor activity of molluscs on fatty acid composition of triglycerides and phospholipids. J Evol Biochem Physiol 45:51-58. doi: 10.1134/S0022093009010049

Asplund J (2011) Snails avoid the medulla of Lobaria pulmonaria and L. scrobiculata due to presence of secondary compounds. Fungal Ecol 4:356-358. doi: 10.1016/j.funeco.2011.05.002

Asplund J, Gauslaa Y (2010) The gastropod Arion fuscus prefers cyanobacterial to green algal parts of the tripartite lichen Nephroma arcticum due to low chemical defence. Lichenologist 42:113-117. doi: 10.1017/S0024282909990284

Asplund J, Johansson O, Nybakken L, et al (2010a) Simulated nitrogen deposition influences gastropod grazing in lichens. Ecoscience 17:83-89. doi: 10.2980/17-1-3331

Asplund J, Solhaug KA, Gauslaa Y (2010b) Optimal defense: snails avoid reproductive parts of the lichen Lobaria scrobiculata due to internal defense allocation. Ecology 91:3100-3105

Asplund J, Wardle DA (2013) The impact of secondary compounds and functional characteristics on lichen palatability and decomposition. J Ecol 101:689-700. doi: $10.1111 / 1365-2745.12075$

Asplund J, Wardle DA (2016) How lichens impact on terrestrial community and ecosystem properties. Biol Rev. doi: 10.1111/brv.12305

Baron M, Albert P, Gorin J, lacomini M (1989) Structural studies on a Galactomannan isolated from the lichen Stereocaulon ramulosum. Agric Biol Chem 53:1751-1758 
Baron M, lacomini M, Fantat ES, Gorin PAJ (1991) Galactomannan, lichenan and isolichenan from the polysaccharide-rich lichen Newropogon aurantiaco-ater. Phytochemistry 30:3125-3126. doi: 10.1016/S0031-9422(00)98266-9

Baur B, Fröberg L, Baur A, et al (2000) Ultrastructure of snail grazing damage to calcicolous lichens. Nord J Bot 20:119-128. doi: 10.1111/j.1756-1051.2000.tb00741.x

Blakeney AB, Harris PJ, Henry RJ, Stone BA (1983) A simple and rapid preparation of alditol acetates for monosaccharide analysis. Carbohydr Res 113:291-299. doi: 10.1016/00086215(83)88244-5

Bodo B, Molho D (1974) Structure of argopsin, new chlorodepsidone from lichen Argopsis megalospora. CR Acad Sci C 278:625-627

Charrier M, Marie A, Guillaume D, et al (2013) Soil calcium availability influences shell ecophenotype formation in the Sub-Antarctic land snail, Notodiscus hookeri. PLoS ONE 8:. doi: 10.1371/journal.pone.0084527

Charrier M, Rouland C (2001) Mannan-degrading enzymes purified from the crop of the brown garden snail Helix aspersa Müller (Gastropoda Pulmonata). J Exp Zool 290:125-135. doi: 10.1002/jez.1042

Chevalier L, Le Coz-Bouhnik M, Charrier M (2003) Influence of inorganic compounds on food selection by the brown garden snail Cornu aspersum (Muller)(Gastropoda: Pulmonata). Malacologia 45:125-132

Coker PD (1967) Damage to lichens by gastropods. Lichenologist 3:428-428. doi: $10.1017 /$ S0024282967000465

Cook RT, Bailey SER, McCrohan CR, et al (2000) The influence of nutritional status on the feeding behaviour of the field slug, Deroceras reticulatum (Müller). Anim Behav 59:167176. doi: $10.1006 /$ anbe.1999.1275

Cook WE, Raisbeck MF, Cornish TE, et al (2007) Paresis and death in elk (Cervus elaphus) due to lichen intoxication in Wyoming. J Wildl Dis 43:498-503. doi: 10.7589/0090-355843.3.498

Denny M (1980) The role of gastropod pedal mucus in locomotion. Nature 285:160-161. doi: $10.1038 / 285160 \mathrm{a} 0$

Flari V, Matoub M, Rouland C (1995) Purification and characterization of a $\beta$-mannanase from the digestive tract of the edible snail Helix lucorum L. Carbohyd Res 275:207-213. doi: $10.1016 / 0008-6215(95) 00136-\mathrm{H}$

Gadea A, Le Pogam P, Biver G, et al (2017) Which specialized metabolites does the native subantarctic gastropod Notodiscus hookeri extract from the consumption of the lichens Usnea taylorii and Pseudocyphellaria crocata? Molecules 22:425. doi: 10.3390/molecules22030425

Galloway DJ (1980) The lichen genera Argopsis and Stereocaulon in New Zealand. Bot Notiser 133:261-279 
Gargas A, DePriest PT, Grube M, Tehler A (1995) Multiple origins of lichen symbioses in fungi suggested by SSU rDNA phylogeny. Science 268:1492-1495. doi: 10.1126/science. 7770775

Gauslaa Y (2005) Lichen palatability depends on investments in herbivore defence. Oecologia 143:94-105. doi: 10.1007/s00442-004-1768-z

Gerson U (1973) Lichen-arthropod associations. Lichenologist 5:434-443. doi: $10.1017 /$ S0024282973000484

Gravot A, Dittami SM, Rousvoal S, et al (2010) Diurnal oscillations of metabolite abundances and gene analysis provide new insights into central metabolic processes of the brown alga Ectocarpus siliculosus. New Phytol 188:98-110. doi: 10.1111/j.14698137.2010.03400.x

Hervé M (2016) RVAideMemoire: diverse basic statistical and graphical functions

Hesbacher S, Baur B, Baur A, Proksch P (1995) Sequestration of lichen compounds by three species of terrestrial snails. J Chem Ecol 21:233-246. doi: 10.1007/BF02036654

Hoebler C, Barry JL, David A, Delort-Laval J (1989) Rapid acid hydrolysis of plant cell wall polysaccharides and simplified quantitative determination of their neutral monosaccharides by gas-liquid chromatography. J Agric Food Chem 37:360-367. doi: $10.1021 /$ jf00086a020

Huneck S, Lamb IM (1975) 1'-Chloropannarin, a new depsidone from Argopsis friesiana: Notes on the structure of pannarin and on the chemistry of the lichen genus Argopsis. Phytochemistry 14:1625-1628. doi: 10.1016/0031-9422(75)85363-5

Hyvärinen M, Koopmann R, Hormi O, Tuomi J (2000) Phenols in reproductive and somatic structures of lichens: a case of optimal defence? Oikos 91:371-375. doi: 10.1034/j.16000706.2000.910217.x

Lamb IM (1974) The lichen genus Argopsis Th. Fr. J Hattori Bot Lab 38:447-462

Lawrey JD (2009) Chemical defense in lichen symbioses. In: White JF, Torres MS (eds) Defensive Mutualism in Microbial Symbiosis. CRC Press, USA, pp 167-176

Lawrey JD (1983) Vulpinic and pinastric acids as lichen antiherbivore compounds: Contrary evidence. Bryologist 86:365. doi: 10.2307/3243250

Le Pogam P, Le Lamer A-C, Legouin B, et al (2016) In situ DART-MS as a versatile and rapid dereplication tool in lichenology: chemical fingerprinting of Ophioparma ventosa. Phytochem Anal 27:354-363. doi: 10.1002/pca.2635

Le Pogam P, Legouin B, Le Lamer A-C, et al (2015) Analysis of the cyanolichen Lichina pygmaea metabolites using in situ DART-MS: from detection to thermochemistry of mycosporine serinol. J Mass Spectrom 50:454-462. doi: 10.1002/jms.3549

Lugan R, Niogret M-F, Kervazo L, et al (2009) Metabolome and water status phenotyping of Arabidopsis under abiotic stress cues reveals new insight into ESK1 function. Plant Cell Environ 32:95-108. doi: 10.1111/j.1365-3040.2008.01898.x 
McKey D (1974) Adaptive patterns in alkaloid physiology. Am Nat 108:305-320. doi: $10.1086 / 282909$

Molnár K, Farkas E (2010) Current results on biological activities of lichen secondary metabolites: a review. Z Naturforsch C 65:157-173

$\mathrm{Ng}$ TPT, Saltin SH, Davies MS, et al (2013) Snails and their trails: the multiple functions of trailfollowing in gastropods. Biol Rev 88:683-700. doi: 10.1111/brv.12023

Nicolai A, Filser J, Lenz R, et al (2012) Composition of body storage compounds influences egg quality and reproductive investment in the land snail Cornu aspersum. Can J Zool 90:1161-1170. doi: 10.1139/z2012-081

Nimis PL, Skert N (2006) Lichen chemistry and selective grazing by the coleopteran Lasioderma serricorne. Environ Exp Bot 55:175-182. doi: 10.1016/j.envexpbot.2004.10.011

Nybakken L, Helmersen A-M, Gauslaa Y, Selås V (2010) Lichen compounds restrain lichen feeding by bank voles (Myodes glareolus). J Chem Ecol 36:298-304. doi: 10.1007/s10886-010-9761-y

Pöykkö H, Hyvärinen M, Bačkor M (2005) Removal of lichen secondary metabolites affects food choice and survival of lichenivorous moth larvae. Ecology 86:2623-2632. doi: $10.1890 / 04-1632$

R Core Team (2017) R: A language and environment for statistical computing. R Foundation for Statistical Computing, Vienna, Austria

Rai A, Bergman B (2002) Cyanolichens. Biol Environ Proc R Ir Acad 102:19-22. doi: http://www.jstor.org/stable/20500135

Renner B (1982) Études microspectrophotométriques sur les céphalodies de Pseudocyphellaria faveolata. Can J Bot 60:630-633. doi: 10.1139/b82-083

Rezanka T, Dembitsky VM (1999) Fatty acids of lichen species from Tian Shan mountains. Folia Microbiol 44:643-646. doi: 10.1007/BF02825654

Rhee KC (2001) Determination of Total Nitrogen. Curr Protoc Food Analyt Chem B1.2:B1.2.1B1.2.9. doi: 10.1002/0471142913.fab0102s00

Roullier C, Chollet-Krugler M, Pferschy-Wenzig E-M, et al (2011) Characterization and identification of mycosporines-like compounds in cyanolichens. Isolation of mycosporine hydroxyglutamicol from Nephroma laevigatum Ach. Phytochemistry 72:1348-1357. doi: 10.1016/j.phytochem.2011.04.002

Rundel PW (1978) The ecological role of secondary lichen substances. Biochem Syst Ecol 6:157-170. doi: 10.1016/0305-1978(78)90002-9

Sanders WB (2001) Lichens: the interface between mycology and plant morphology: whereas most other fungi live as an absorptive mycelium inside their food substrate, the lichen fungi construct a plant-like body within which photosynthetic algal symbionts are cultivated. Bioscience 51:1025-1035. doi: 10.1641/00063568(2001)051[1025:LTIBMA]2.0.CO;2 
Schoch CL, Seifert KA, Huhndorf S, et al (2012) Nuclear ribosomal internal transcribed spacer (ITS) region as a universal DNA barcode marker for Fungi. Proc Natl Acad Sci 109:6241-6246. doi: 10.1073/pnas.1117018109

Slansky F (1979) Effect of the lichen chemicals atranorin and vulpinic acid upon feeding and growth of larvae of the yellow-striped armyworm, Spodoptera ornithogalli. Environ Entomol 8:865-868. doi: 10.1093/ee/8.5.865

Solhaug KA, Gauslaa Y (2001) Acetone rinsing-a method for testing ecological and physiological roles of secondary compounds in living lichens. Symbiosis 30:301-315

Solhaug KA, Gauslaa Y (2012) Secondary lichen compounds as protection against excess solar radiation and herbivores. In: Lüttge $U$, Beyschlag W, Büdel B, Francis D (eds) Progress in Botany, 73rd edn. Springer Berlin Heidelberg, pp 283-304

Speiser B (2001) Food and feeding behaviour. In: Baker G (ed) The Biology of Terrestrial Molluscs, Baker GM. CAB International, UK, pp 259-288

Stocker-Wörgötter E (2008) Metabolic diversity of lichen-forming ascomycetous fungi: culturing, polyketide and shikimatemetabolite production, and PKS genes. Nat Prod Rep 25:188200. doi: 10.1039/B606983P

Van den Berg RA, Hoefsloot HC, Westerhuis JA, et al (2006) Centering, scaling, and transformations: improving the biological information content of metabolomics data. BMC Genomics 7:142. doi: 10.1186/1471-2164-7-142

Vu TH, Catheline D, Delmail D, et al (2016) Gas chromatographic analysis to compare the fatty acid composition of fifteen lichen species, with a focus on Stereocaulon species. Lichenologist 48:323-337. doi: 10.1017/S0024282916000141

Wieners PC, Bilger W, Gauslaa Y (2018) Carbon-based secondary compounds in the lichen Hypogymnia physodes deter detrivorous woodlice. Fungal Ecol 31:54-58. doi: 10.1016/j.funeco.2017.11.002

Yosioka I, Hino K, Fujio M, Kitagawa I (1973) The structure of caloploicin, a new lichen trichlorodepsidone. Chem Pharm Bull 21:1547-1553. doi: 10.1248/cpb.21.1547

FIGURES

Fig. 1 Argopsis friesiana (Stereocaulaceae) entire thallus (a) and cephalodia (b) before and after 602 snail consumption. Phyllocladia $(\mathrm{Ph})$, algal layer of pseudopodetia $(\mathrm{Pa})$ and cephalodia $(\mathrm{Ce})$ 603 were consumed while apothecia (Ap) and fungal axis of pseudopodetia (Pf) remained 604 untouched. The specimens were dry before consumption (a-1 and b-1) and wet after snail 
feeding ( $a-2$ and $b-2)$. The black line shows the transversal section of a pseudopodetium to discriminate between the cortical layer $(\mathrm{Pa})$ and the fungal axis $(\mathrm{Pf})$.

Fig. 2 Differential grazing and level of damage (LD) to Argopsis friesiana by the snail Notodiscus hookeri. $\mathrm{N}=15$ lichen thalli given to snails. $\mathrm{Pa}=$ algae-containing layer of pseudopodetia, $\mathrm{Ph}=$ phyllocladia, $\mathrm{Ce}=$ cephalodia; apothecia and medullar part of pseudopodetia that remained untouched are not shown. The level damage classes are LD1 = minimum damage $(>0 \%$ and $<25 \%)$, LD2 $=$ medium damage $(25 \%-50 \%)$ and LD3 = high damage $(>50 \%)$.

Fig. 3 Graphs of the Powered Partial Least Squares - Discriminant Analysis (PPLS-DA) performed on the chemical composition of the four lichen parts of Argopsis friesiana. a. Score plot 1-2: $\mathrm{Ap}=$ apothecia, $\mathrm{Ce}=$ cephalodia; $\mathrm{Ph}+\mathrm{Pa}=$ phyllocladia + cortical algal layer, $\mathrm{Pf}=$ fungal layer of pseudopodetia. b. Corresponding loading plots of metabolites, including secondary metabolites, amino acids, free sugars and polyols, sugar-forming polysaccharides, saturated and unsaturated fatty acids. Saturated fatty acids (FAsat) included C14:0, C15:0, C16:0, isoC17:0, C18:0, C20:0, C22:0, C23:0, C24:0. Abbreviations used are given in Table 1. For clarity, in the presence of collinearity $(\geq 95 \%)$, only one of the two correlated variables was considered (Table S3). c. Score plot 2-3 and d. corresponding loading plots.

SUPPLEMENTARY DATA

626 The following supplementary data are related to this article: see Supplementary data file

627 Online resource 1. Fig. S1: Study sites on Possession Island, which belongs to Crozet 628 Archipelago $\left(45^{\circ} 30^{\prime}-46^{\circ} 30^{\prime} \mathrm{S} ; 50^{\circ} 00^{\prime}-52^{\circ} 30^{\prime} \mathrm{E}\right)$ in the Subantarctic region.

629 Online Resource 2: Chemical and spectroscopic data. Fig. S2: Three main secondary metabolites of Argopsis friesiana: the chlorodepsidones argopsin (1) and caloploicin (2) and the 
depside atranorine (3). Fig. S3: NMR spectra $\left({ }^{1} \mathrm{H}, 300 \mathrm{MHz}\right.$ and $\left.{ }^{13} \mathrm{C}, 75 \mathrm{MHz}\right)$ of argopsin in $\mathrm{CDCl}_{3}$ and argopsin formula, Table S1: ${ }^{1} \mathrm{H}$ NMR $(300 \mathrm{MHz})$ and ${ }^{13} \mathrm{C} \mathrm{NMR}(75 \mathrm{MHz})$ data for argopsin. Data recorded inCDCl 3 , $\delta$ in ppm; Fig. S4: NMR spectra $\left({ }^{1} \mathrm{H}, 500 \mathrm{MHz}\right.$ and ${ }^{13} \mathrm{C}, 125$ $\mathrm{MHz}$ ) of caloploicin in acetone ( $d_{6}$-acetone) and caloploicin formula, Table S2: ${ }^{1} \mathrm{H}$ NMR (500 $\mathrm{MHz}$, cryo) and ${ }^{13} \mathrm{C}$ NMR $(125 \mathrm{MHz})$ data for caloploicin. Data recorded in acetone- $d 6$, $\delta$ in ppm, Table S3: Results of exact mass measurements in negative-ion mode DART-HRMS of the molecules retrieved in Argopsis friesiana, Table S4: Each secondary metabolite in the four lichen 638 parts, calculated as a percentage of all the compounds detected in this chemical group.

639 Online Resource 3: Multivariate analysis supplementary data. Fig. S5: Projection to the axis PC1 640 of the metabolites analysed by PPLS-DA. Fig. S6: Projection to the axis PC2 of the metabolites 641 analysed by PPLS-DA. ; Fig. S7: Projection to the axis PC3 of the metabolites analysed by 642 PPLS-DA. Table S5: Correlated compounds (> 95\%) in the PPLS-DA analysis from the data set 643 of the compounds identified in the lichen $A$. friesiana.

644 Online Resource 4: Fig. S8: Scanning Electron Microscopy of the radula of Notodiscus hookeri, 645 extracted from the buccal mass. 

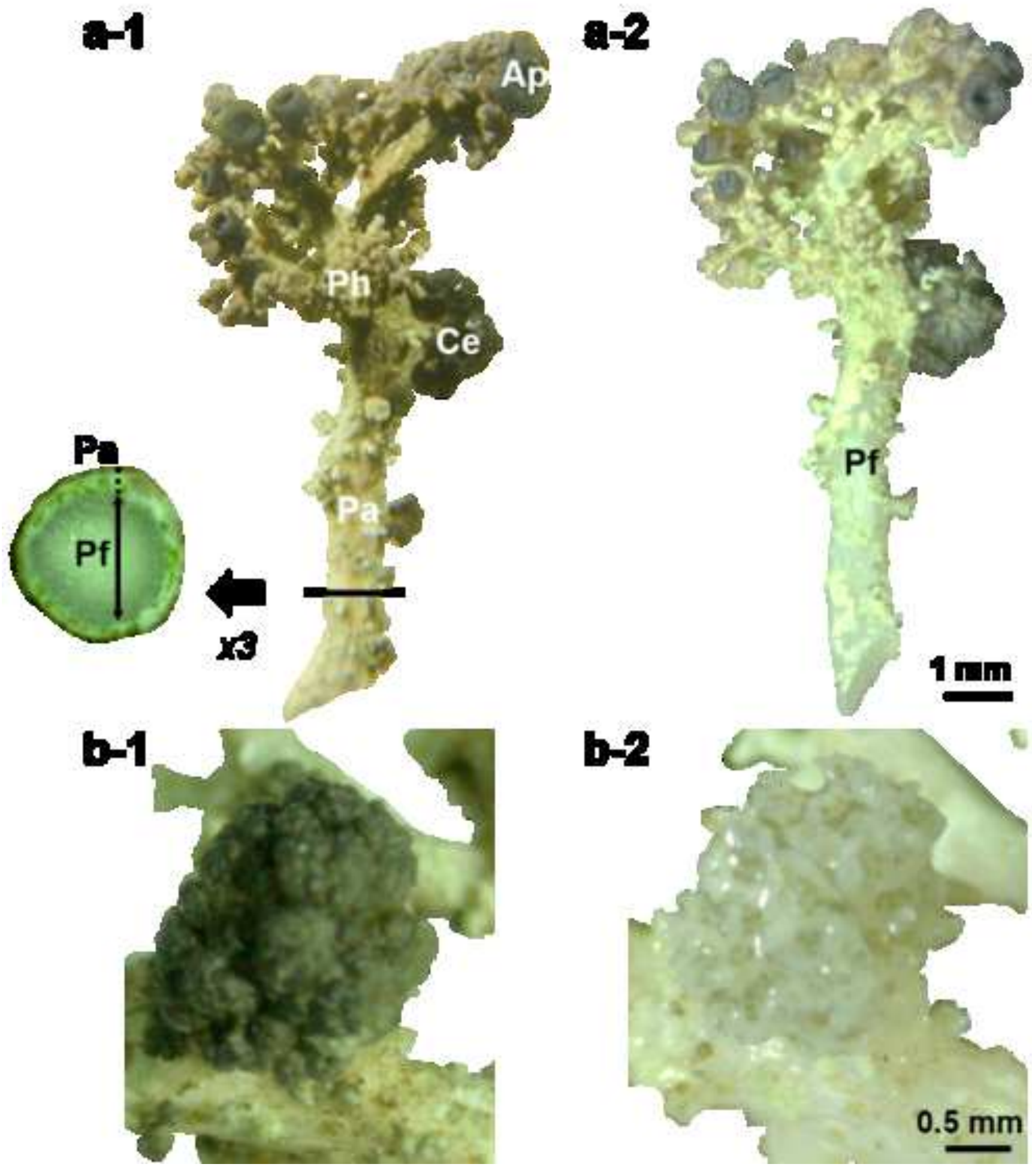


\section{$\square \mathrm{Pa} \square \mathrm{Ph}$ 口Ce}

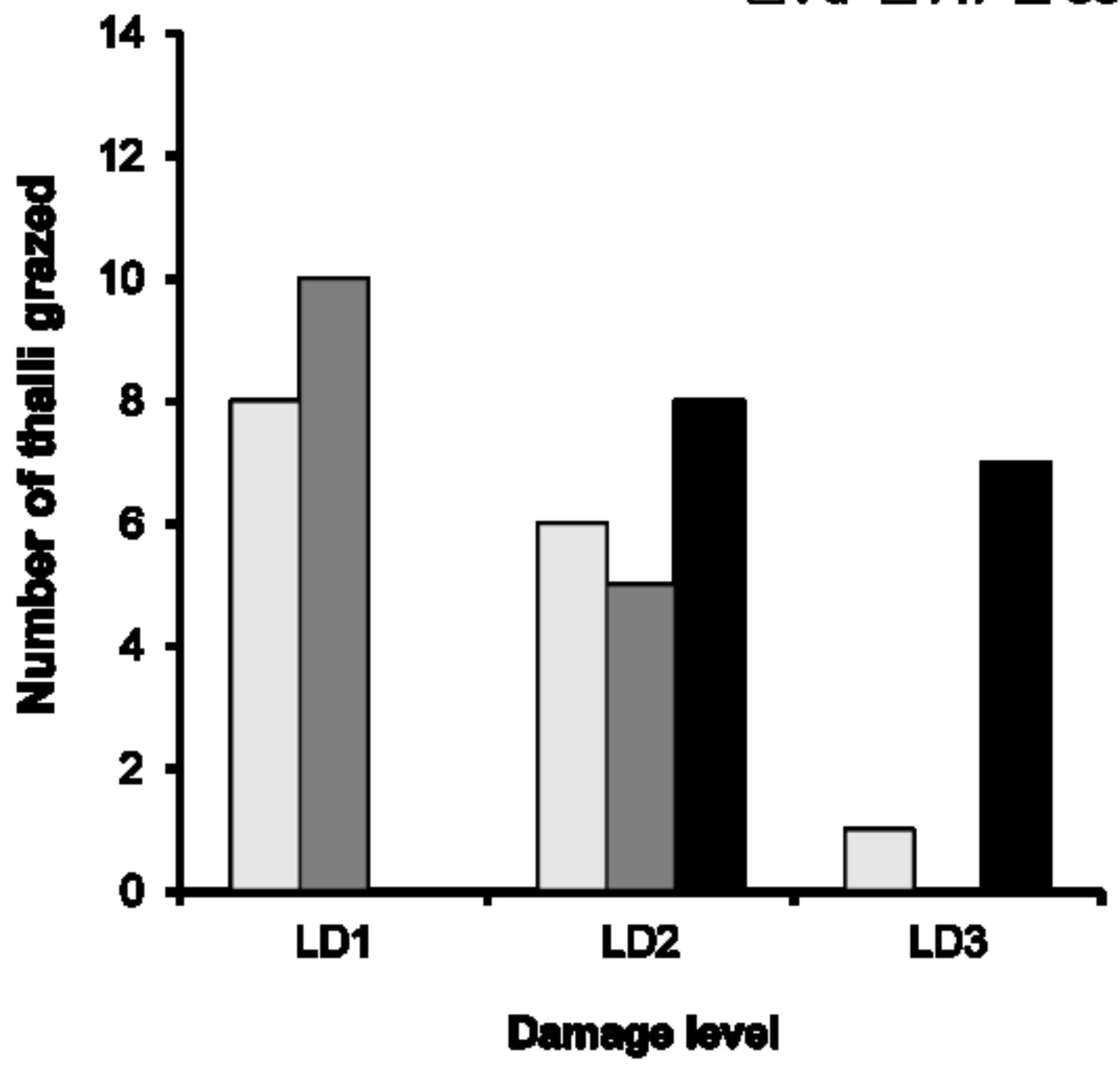



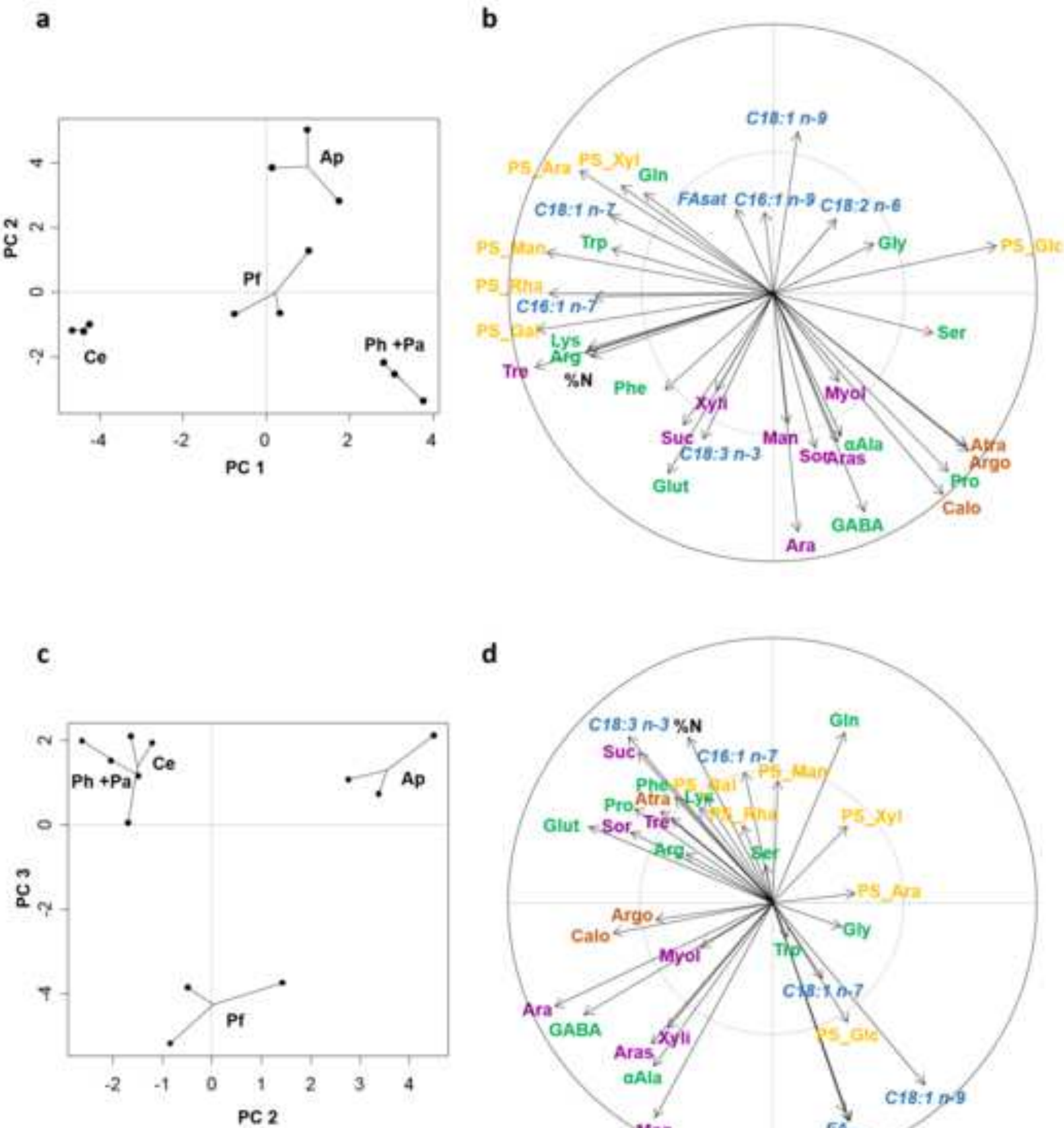

d

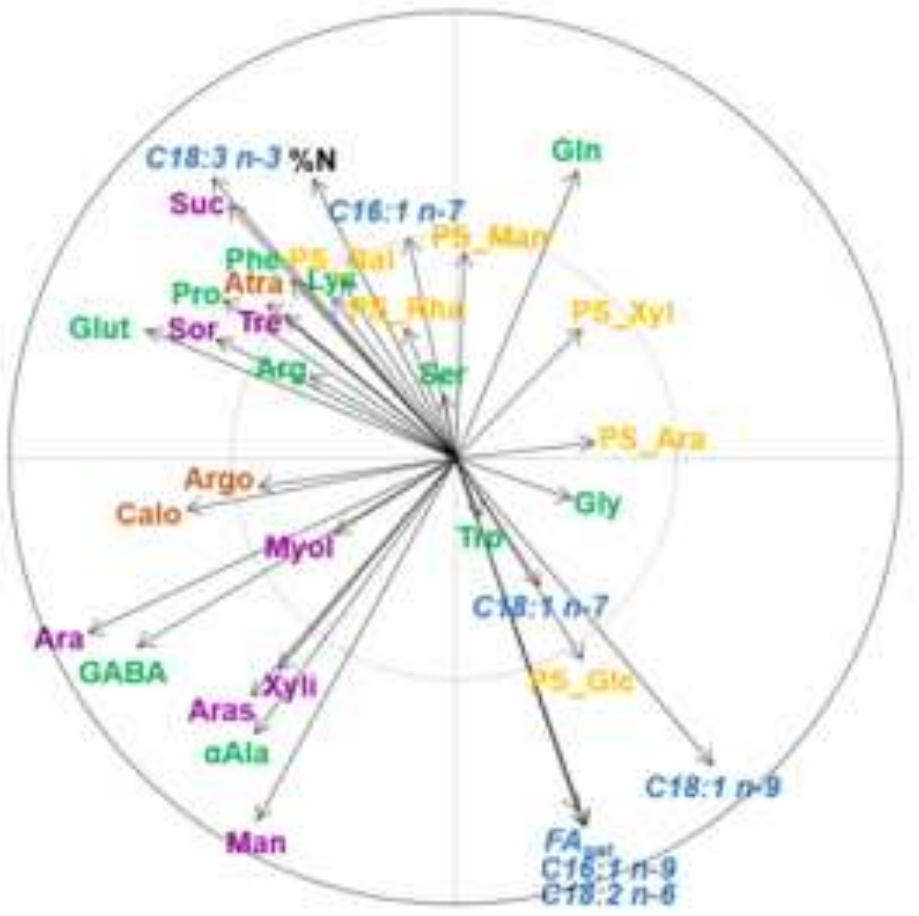




\section{Figures}

INTRATHALLINE METABOLITE PROFILES IN THE LICHEN Argopsis friesiana SHAPE GASTROPOD GRAZING PATTERNS.

Alice GADEA ${ }^{1,2}$, Anne-Cécile LE LAMER ${ }^{3}$, Sophie LE GALL ${ }^{4}$, Catherine JONARD ${ }^{5}$, Solenn FERRON¹, Daniel CATHELINE ${ }^{6}$, Damien ERTZ7 , Pierre LE POGAM ${ }^{8}$, Joël BOUSTIE ${ }^{1}$, Françoise LE DEVEHAT ${ }^{1, \dagger}$ and Maryvonne CHARRIER $^{2, \dagger}$ 

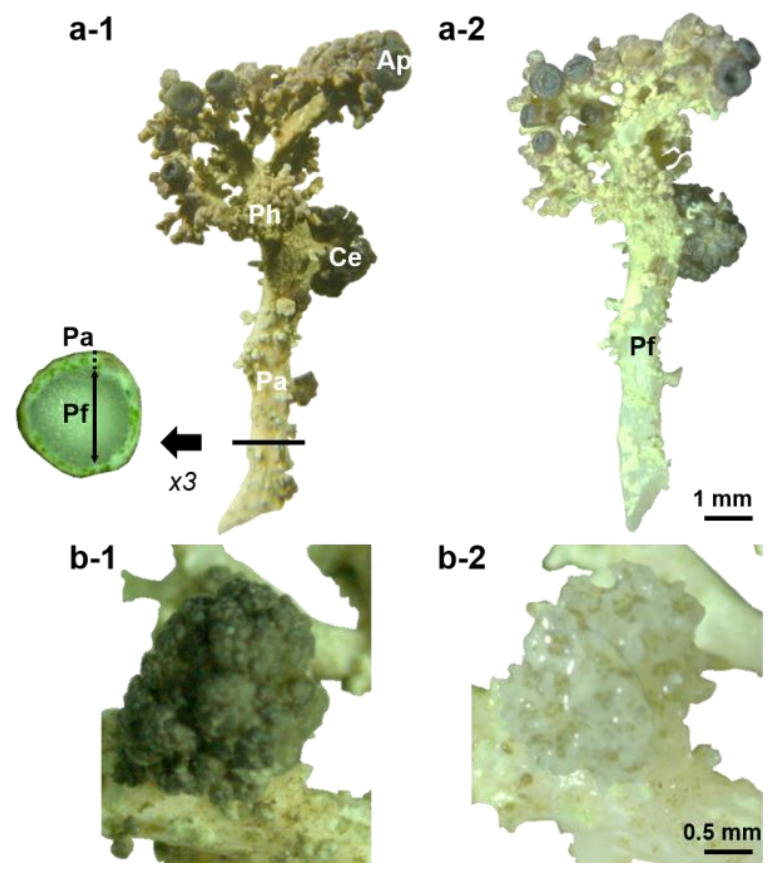

Fig. 1 Argopsis friesiana (Stereocaulaceae) entire thallus (a) and cephalodia (b) before and after snail consumption. Phyllocladia (Ph), algal layer of pseudopodetia (Pa) and cephalodia $(\mathrm{Ce})$ were consumed while apothecia $(\mathrm{Ap})$ and fungal axis of pseudopodetia (Pf) remained untouched. The specimens were dry before consumption ( $a-1$ and $b-1)$ and wet after snail feeding ( $a-2$ and $b-2)$. The black line shows the transversal section of a pseudopodetium to discriminate between the cortical algal layer $(\mathrm{Pa})$ and the fungal axis $(\mathrm{Pf})$. 


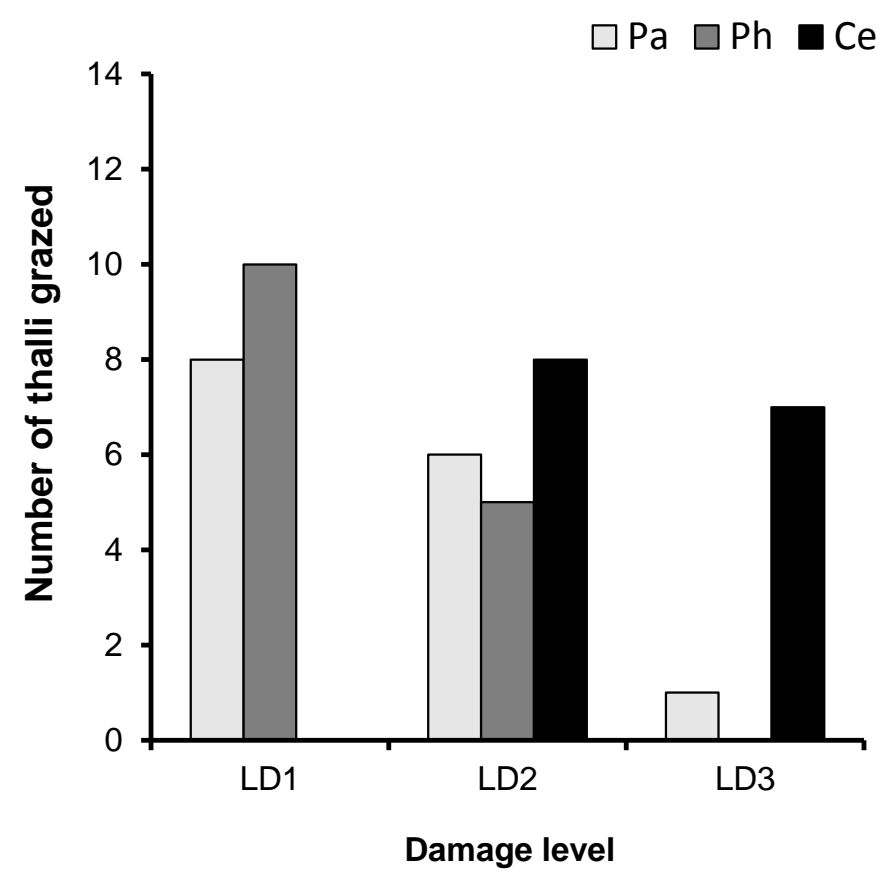

Fig. 2 Differential grazing and level of damage (LD) to Argopsis friesiana by the snail Notodiscus hookeri. $\mathrm{N}=15$ lichen thalli given to snails. $\mathrm{Pa}=$ algae-containing layer of pseudopodetia, $\mathrm{Ph}=$ phyllocladia, $\mathrm{Ce}=$ cephalodia; apothecia and medullar part of pseudopodetia that remained untouched are not shown. The level damage classes are LD1 $=$ minimum damage $(>0 \%$ and $<25 \%)$, LD2 = medium damage $(25 \%-50 \%)$ and LD3 $=$ high damage $(>50 \%)$. 

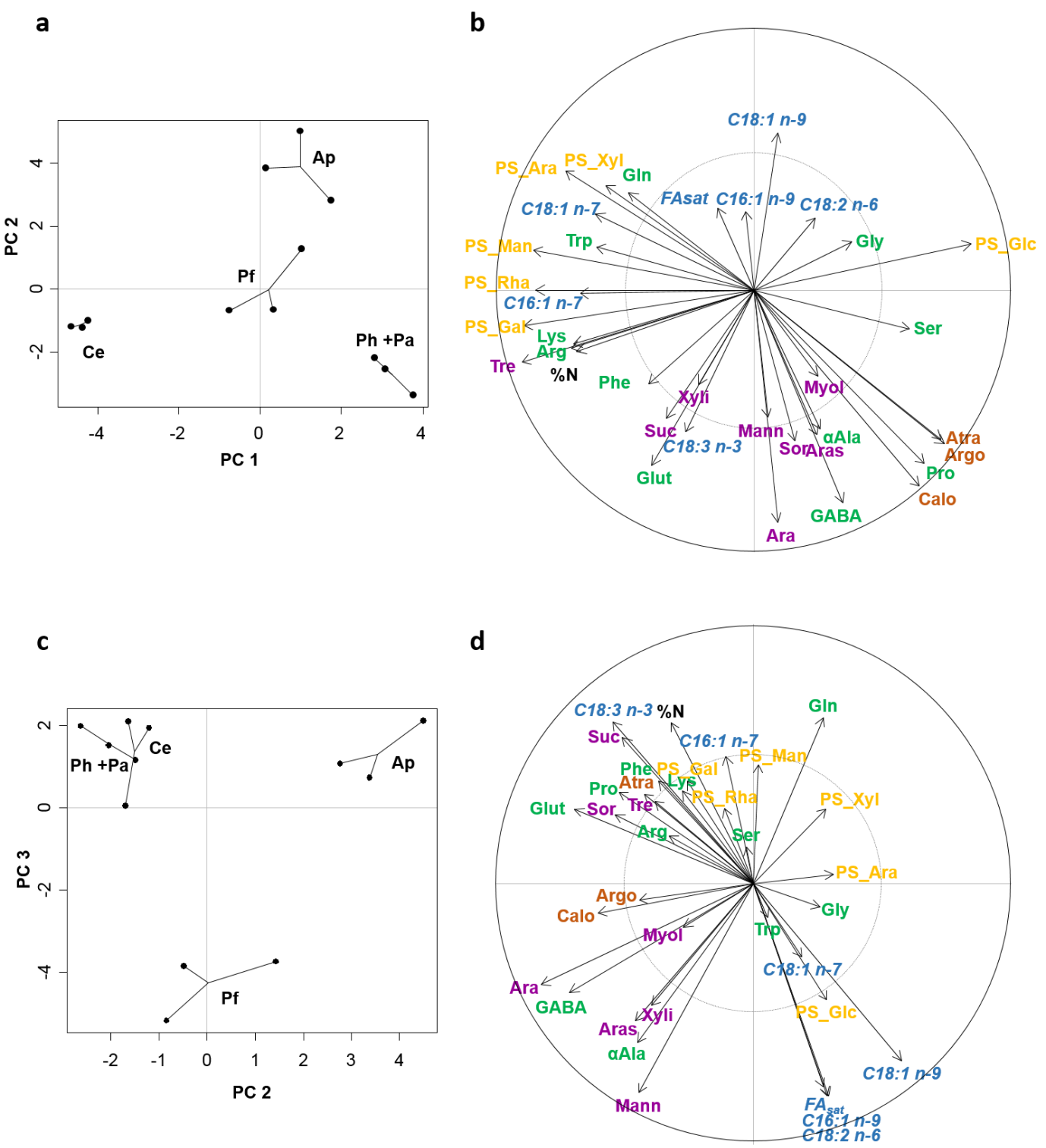

Fig. 3 Graphs of the Powered Partial Least Squares - Discriminant Analysis (PPLS-DA) performed on the chemical composition of the four lichen parts of Argopsis friesiana. a. Score plot 1-2: $\mathrm{Ap}=$ apothecia, $\mathrm{Ce}=$ cephalodia; $\mathrm{Ph}+\mathrm{Pa}=$ phyllocladia + cortical algal layer, $\mathrm{Pf}=$ fungal layer of pseudopodetia. b. Corresponding loading plots of metabolites, including secondary metabolites, amino acids, free sugars and polyols, sugar-forming polysaccharides, saturated and unsaturated fatty acids. Saturated fatty acids (FA sat $)$ included C14:0, C15:0, C16:0, isoC17:0, C18:0, C20:0, C22:0, C23:0, C24:0. Abbreviations used are given in Table 1. For clarity, in the presence of collinearity ( $\geq 95 \%$ ), only one of the two correlated variables was considered (Table S3). c. Score plot 2-3 and d. corresponding loading plots. 

Table 1 Data set of the compounds identified in the four parts of the lichen Argopsis friesiana $(\mathrm{Ap}=$ apothecia, $\mathrm{Ce}=$ cephalodia, $\mathrm{Ph}=$ phyllocladia, $\mathrm{Pa}=$ algal layer of pseudopodetia and $\mathrm{Pf}=$ fungal axis of pseudopodetia): secondary metabolites, free sugars and polyols, amino acids, fatty acids and sugar forming polysaccharides. Values are means $(n=3$ replicates) in $\mathrm{mg} \cdot \mathrm{g}^{-1} \mathrm{dry}$ mass with (minimum - maximum) in brackets, except the secondary metabolites, which are expressed in Area Under the Curve (samples: $0.5 \mathrm{mg} \cdot \mathrm{ml}^{-1}$ ) *extraction yield $\left(\times 10^{5}\right)$. Total polysaccharides (Total PS) and total nitrogen (TN) are expressed in percentage of DM. The sign '-' means that the metabolite was not detected.

\begin{tabular}{|c|c|c|c|c|}
\hline \multicolumn{2}{|c|}{ Secondary Metabolites (Area x 105): Ap } & $\frac{\text { Pf }}{1.87(1.16-2.54)}$ & $\frac{\mathrm{Ph}+\mathrm{Pa}}{41.50(32.12-52.18)}$ & $\frac{\mathrm{Ce}}{1.31(1.08-1.47)}$ \\
\hline Argopsin (Argo) & $1.14(0.26-2.41)$ & $2.46(0.57-3.69)$ & $7.23(5.60-8.75)$ & $0.40(0.35-0.42)$ \\
\hline Caloploicin (Calo) & $0.54(0.21-1.03)$ & $2.57(0.86-4.82)$ & $6.38(5.47-7.20)$ & $0.55(0.47-0.66)$ \\
\hline Free Sugars/Polyols: & Ap & Pf & $\mathrm{Ph}+\mathrm{Pa}$ & $\mathrm{Ce}$ \\
\hline Arabitol (Ara) & $33.41(25.82-39.24)$ & $89.70(58.60-133.29)$ & $91.86(87.13-100.73)$ & $178.02(57.6-399.02)$ \\
\hline Mannitol (Man) & $1.08(1.03-1.13)$ & $3.50(2.63-4.76)$ & $1.97(1.66-2.13)$ & $11.13(1.69$ - 29.99) \\
\hline Myo-inositol (Myo) & $0.02(0-0.05)$ & $0.07(0-0.13)$ & $0.10(0-0.17)$ & $0.11(0-0.33)$ \\
\hline Sucrose (Sac) & $0.04(0-0.13)$ & - & $0.13(0-0.20)$ & $0.28(0.24-0.32)$ \\
\hline Xylitol (Xyl) & - & $0.19(0-0.35)$ & $0.07(0-0.22)$ & $0.41(0-1.24)$ \\
\hline Free Amino Acids: & Ap & Pf & $\mathrm{Ph}+\mathrm{Pa}$ & $\mathrm{Ce}$ \\
\hline$\alpha$-Alanine ( $\alpha$ Ala) & $0.08(0.04-0.13)$ & $0.19(0.10-0.29)$ & $0.13(0.12-0.15)$ & $0.09(0.08-0.09)$ \\
\hline Arginine (Arg) & - & - & - & $0.11(0-0.19)$ \\
\hline GABA & $0.20(0.17-0.25)$ & $0.40(0.38-0.44)$ & $0.44(0.40-0.48)$ & $0.27(0.23-0.30)$ \\
\hline Glutamine (GIn) & $0.12(0.07-0.16)$ & - & $0.03(0-0.10)$ & $0.16(0.16-0.17)$ \\
\hline Glutamate (Glut) & $0.14(0.11-0.15)$ & $0.18(0.06-0.30)$ & $0.25(0.14-0.33)$ & $0.34(0.31-0.37)$ \\
\hline Tryptophan (Trp) & $0.10(0-0.17)$ & $0.11(0-0.17)$ & $0.03(0-0.08)$ & $0.15(0.08-0.26)$ \\
\hline Fatty Acids: & Ap & Pf & $\mathrm{Ph}+\mathrm{Pa}$ & $\mathrm{Ce}$ \\
\hline $\mathrm{C} 14: 0$ & $0.01(0.01-0.02)$ & $0.03(0.02-0.03)$ & $0.03(0.02-0.04)$ & $0.05(0.02-0.08)$ \\
\hline C15:0 & $0.01(0-0.01)$ & $0.02(0.02-0.02)$ & $0.02(0.01-0.03)$ & $0.02(0.01-0.04)$ \\
\hline $\mathrm{C} 16: 0$ & $0.14(0.09-0.23)$ & $0.34(0.32-0.36)$ & $0.43(0.33-0.53)$ & $0.46(0.26-0.84)$ \\
\hline $\mathrm{C} 17: 0$ & $0.01(0-0.01)$ & $0.02(0.01-0.02)$ & $0.02(0.01-0.04)$ & $0.02(0.01-0.05)$ \\
\hline C18:0 & $0.09(0.06-0.14)$ & $0.25(0.24-0.26)$ & $0.29(0.23-0.32)$ & $0.24(0.14-0.40)$ \\
\hline
\end{tabular}




\begin{tabular}{|c|c|c|c|c|}
\hline C20:0 & $0.01(0.01-0.02)$ & $0.03(0.02-0.03)$ & $0.03(0.02-0.04)$ & $0.03(0.01-0.05)$ \\
\hline $\mathrm{C} 22: 0$ & $0.02(0.01-0.05)$ & $0.05(0.03-0.06)$ & $0.07(0.04-0.09)$ & $0.05(0.03-0.09)$ \\
\hline C23:0 & $0.01(0-0.01)$ & $0.02(0.01-0.02)$ & $0.02(0-0.03)$ & $0.01(0-0.03)$ \\
\hline $\mathrm{C} 24: 0$ & $0.01(0-0.02)$ & $0.03(0.02-0.04)$ & $0.05(0.04-0.06)$ & $0.03(0.01-0.05)$ \\
\hline Total Saturated $\left(\mathrm{FA}_{\mathrm{sat}}\right)$ & $0.30(0.19-0.51)$ & $0.78(0.75-0.81)$ & $0.96(0.81-1.14)$ & $0.90(0.51-1.63)$ \\
\hline C18:3n-3 & $0.01(0.01-0.01)$ & - & $0.13(0.09-0.15)$ & $0.10(0.06-0.15)$ \\
\hline$C 16: 2 n-6$ & - & - & - & $0.01(0.01-0.02)$ \\
\hline$C 18: 2 n-6$ & $0.26(0.24-0.27)$ & $0.95(0.86-1.01)$ & $1.15(0.95-1.45)$ & $0.45(0.37-0.59)$ \\
\hline C16:1 n-7 & $0.01(0.01-0.01)$ & - & $0.03(0.02-0.03)$ & $0.06(0.05-0.09)$ \\
\hline C18:1 n-9 & $0.07(0.06-0.07)$ & $0.14(0.12-0.16)$ & $0.16(0.13-0.19)$ & $0.10(0.07-0.15)$ \\
\hline $\mathrm{FA}_{\text {unsat }}(\mathrm{n}-3)$ & $0.01(0.01-0.01)$ & - & $0.14(0.11-0.16)$ & $0.10(0.06-0.15)$ \\
\hline FA unsat $(n-6)$ & $0.26(0.24-0.27)$ & $0.95(0.86-1.01)$ & $1.15(0.95-1.45)$ & $0.46(0.38-0.61)$ \\
\hline FA unsat $(n-7)$ & $0.02(0.02-0.02)$ & $0.03(0.02-0.03)$ & $0.07(0.06-0.08)$ & $0.13(0.10-0.18)$ \\
\hline FA unsat $(n-9)$ & $0.08(0.07-0.08)$ & $0.17(0.14-0.18)$ & $0.19(0.16-0.22)$ & $0.13(0.09-0.19)$ \\
\hline $\begin{array}{l}\text { Total Unsaturated } \\
\text { (FA }\end{array}$ & $0.36(0.33-0.38)$ & $1.15(1.05-1.18)$ & $1.55(1.28-1.90)$ & $0.81(0.65-1.13)$ \\
\hline Total FA & $0.66(0.56-0.83)$ & $1.93(1.84-2.01)$ & $2.50(2.08-2.83)$ & $1.71(1.16-2.76)$ \\
\hline Mannose (PS_Mans) & $116.54(112.02-122.58)$ & $77.24(66.43-85.07)$ & $74.41(73.73-75.31)$ & $182.82(150.65-201.89)$ \\
\hline Rhamnose (PS_Rhas) & $4.15(3.89-4.54)$ & $4.02(3.66-4.48)$ & $3.62(2.88-4.06)$ & $6.53(5.00-7.29)$ \\
\hline Xylose (PS_Xyls) & $9.76(7.93-11.16)$ & $7.00(4.20-10.39)$ & $5.36(4.99-5.78)$ & $10.04(8.15-12.60)$ \\
\hline Total PS (\%) & 72.39 (67.83 - 76.95) & 71.94 (66.17 - 77.71) & $66.55(63.64-69.46)$ & $54.27(50.60-57.63)$ \\
\hline Total Nitrogen (TN) (\%) & $0.68(0.57-0.85)$ & $0.37(0.36-0.38)$ & $0.66(0.63-0.72)$ & $1.62(1.46-1.78)$ \\
\hline
\end{tabular}


Supplementary Material

Supplementary Material

(1)
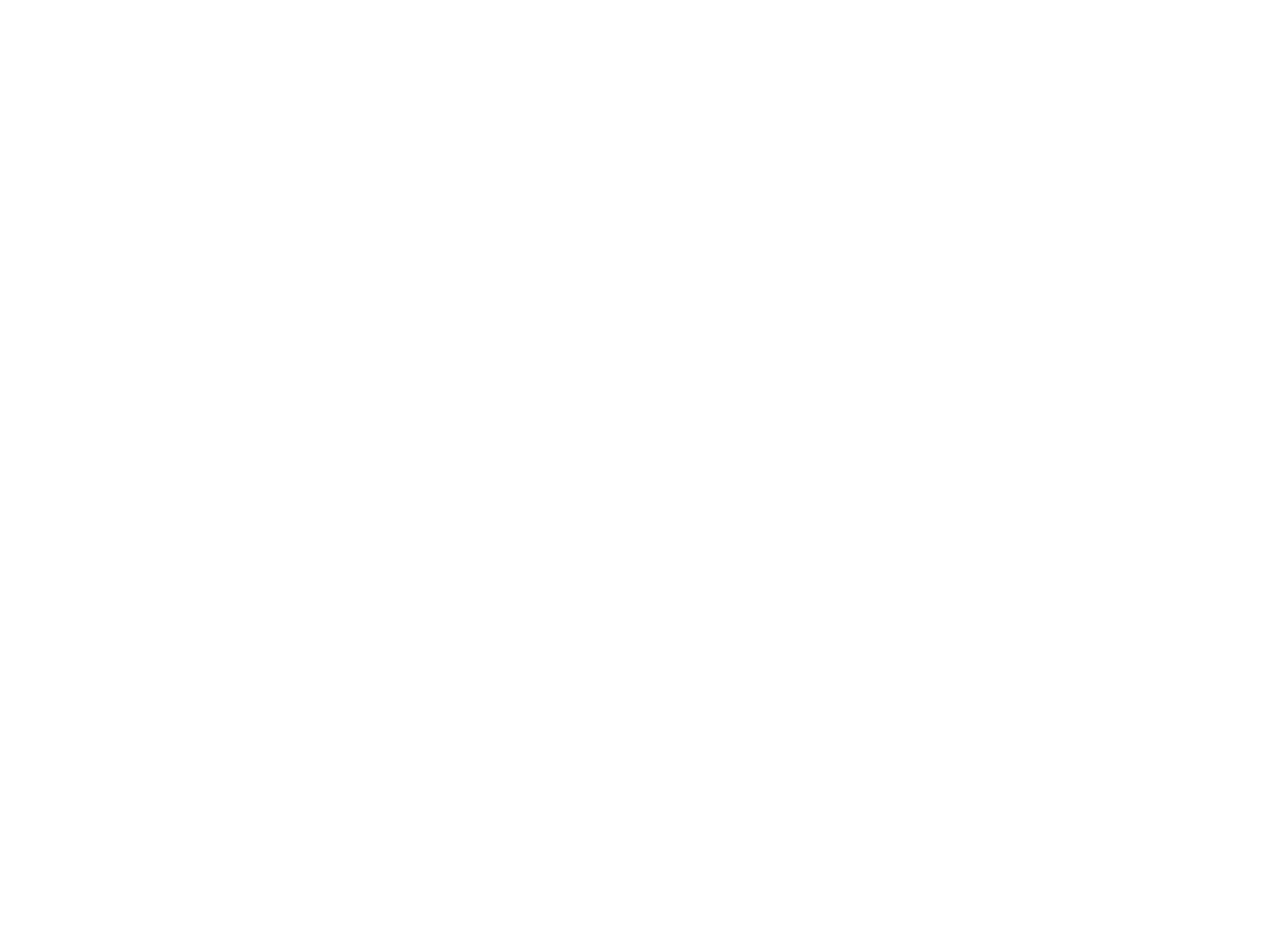

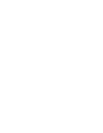
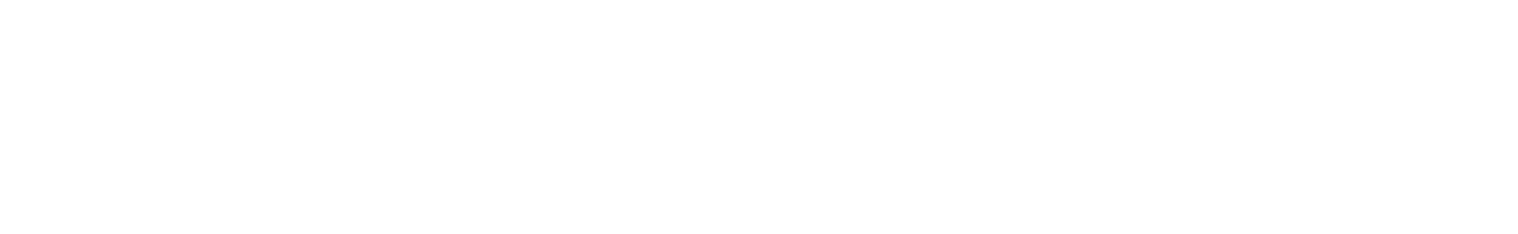

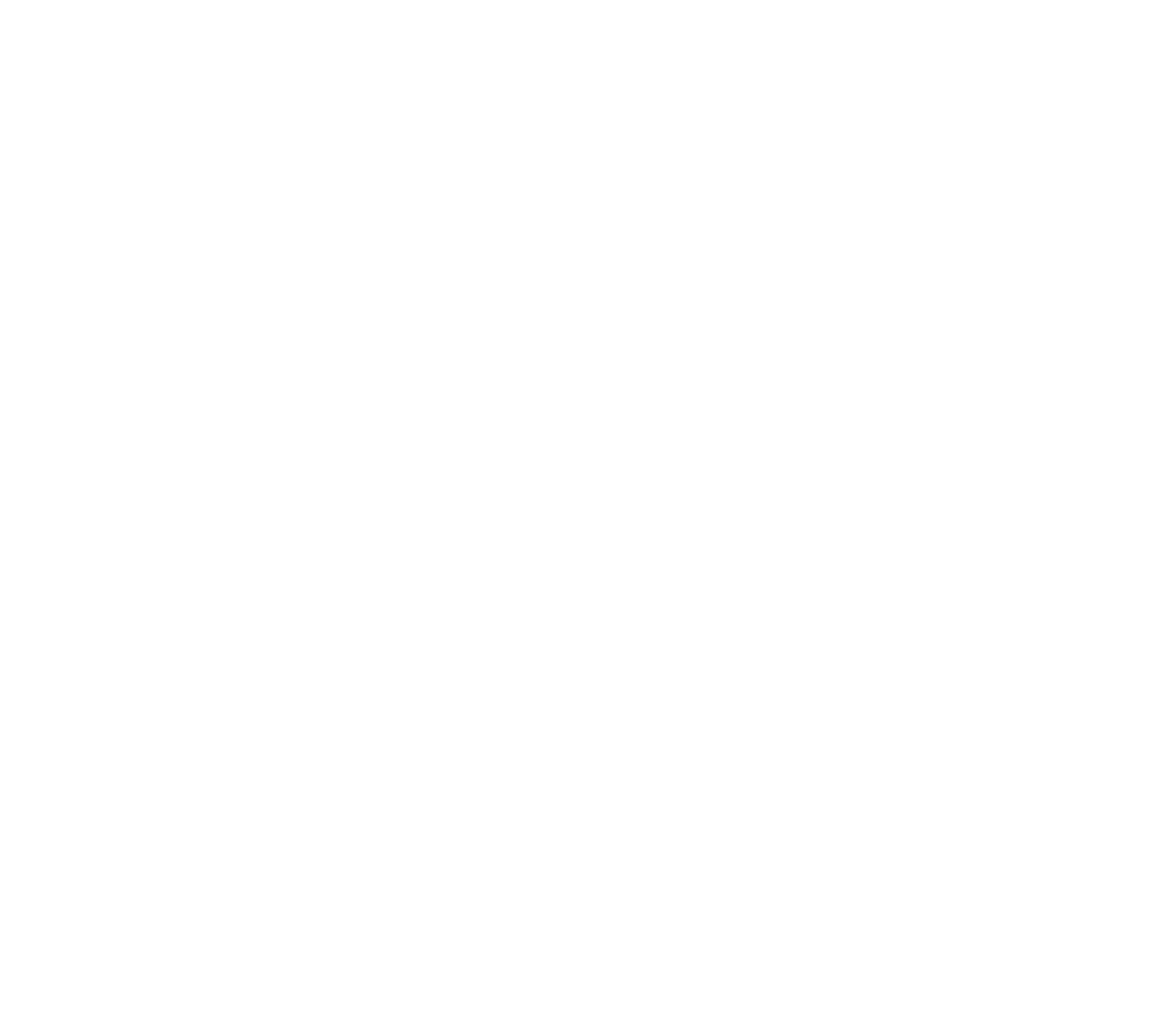

